\title{
Importancia de judicializar los casos de violación de derechos humanos ante la Corte Interamericana de Derechos Humanos
}

\author{
José Bernabé Pineda Coronado' \\ Docente Utec \\ jose.pineda@utec.edu.sv \\ Recibido: 22/11/2016 - Aceptado: 24/01/2017
}

Este artículo está basado en investigación de cátedra realizada durante el ciclo 01-2016.

\section{Resumen}

El objetivo de la investigación era determinar cuál es la importancia de judicializar los casos de violación de derechos humanos ante la corte Interamericana de Derechos Humanos (CIDH). Los participantes de la investigación fueron los estudiantes que cursan la materia de Derecho Internacional Público y Privado, de la licenciatura en Ciencias Jurídicas de la Universidad Tecnológica de El Salvador, tanto de la sección 01 como de la 02. De la población indicada, se seleccionó una muestra de 840 estudiantes; a partir de esta se realizó una submuestra para cada una de las secciones, dando como resultado para la sección 01 un total de 32 alumnos, y para la 02, un total de 27. Entre los hallazgos de la investigación de campo de este estudio, estuvo el hecho de que las personas encuestadas conocen que el papel de la CIDH se ve limitado únicamente a la interpretación y aplicación de la Convención Americana sobre Derechos Humanos y a sancionar los casos de violación de derechos humanos.

\section{Palabras clave}

Derechos humanos, administración de justicia, violación de los derechos humanos-derecho internacional, derechos humanos, El Salvador.

\section{Abstract}

This investigation was aimed at determining what the importance of judicializing human rights violation cases is before the Inter-American Court of Human Rights (IACHR). The team of researchers included the students enrolled in the subject Public and Private International Law, who belong to the Major in Law at Universidad Tecnológica de El Salvador. Two groups of the same subject participated. From the population, a sample of 840 students was taken; then, a sub-sample for each group was selected. From the first group, a total of 32 students were chosen; from the second group, a total of 27 . One of the findings of the field research included the following: the people who were surveyed are aware of the fact that the role of the IACHR is limited only to the interpretation and application of the American Convention of Human Rights and to the punishment of cases involving human rights violations.

\section{Keywords}

Human rights, administration of justice, human rights violations - international law, human rights-, El Salvador.

\footnotetext{
${ }^{1}$ Docente de la Facultad de Derecho de la Universidad Tecnológica (Utec). Especialista en Derecho Internacional Público y Privado.
} 


\section{Introducción}

La importancia de judicializar los casos de violación de derechos humanos no solo radica en atribuir a los Estados una responsabilidad internacional para reparar el daño ocasionado a las víctimas, sino también radica en el desprendimiento y protección del derecho individual de las víctimas y de toda la colectividad internacional a la "verdad".

Según Quinteros (2010), en su libro Judicialización de violaciones de derechos humanos, el proceso de internacionalización de los derechos humanos tiene un punto de partida muy concreto: los Estados no ofrecen suficientes garantías para la protección de los derechos humanos, por eso es necesario desarrollar un sistema internacional de tutela de tales derechos. Ello ha implicado contar con instrumentos declarativos, tratados internacionales, órganos internacionales de protección, tribunales internacionales, entre otros; y desde se dan pautas para lograr una mejor garantía de los derechos humanos.

Para las normas internacionales la importancia de judicializar los casos de violaciones a los derechos humanos no solo se trata de una consecuencia o un efecto a la transgresión de esas normas, si no que se trata al mismo tiempo de investigar, procesar y sancionar a los responsables de dichas violaciones, incorporando al mismo tiempo la importancia de satisfacer el derecho subjetivo de las víctimas, al cual nos referíamos al párrafo anterior, en el que las víctimas, sus familias y la comunidad en general tiene que saber por qué y cómo sucedieron esas violaciones, y qué hace el Estado para remediarlo, permitiendo a la vez que la comunidad cree un sentimiento de responsabilidad social frente a los casos de violación de los derechos humanos, evitando que se perciba que la violencia solo puede ser resuelta con más violencia.

De este modo es que el presente trabajo de investigación pretende describir el Derecho Internacional general y el Derecho Internacional de los derechos humanos, en cuanto a la importancia que existe ante la obligación de los Estados de judicializar los casos de violación a los derechos humanos con ayuda de organismos de índole internacional, como la Corte Interamericana de Derechos Humanos, cuyo propósito es aplicar e interpretar la Convención Americana sobre Derechos Humanos y otros tratados afines.

\section{Método}

Este estudio se llevó a cabo mediante un método científico, ya que se siguió una serie de pasos para la investigación.

El diseño de la investigación es no experimental porque no se hará una manipulación de variables, si no que una observación del fenómeno de estudio, luego se realizará un análisis de estudio. Es decir, en la investigación no se harán cambios intencionales de las variables.

El tipo de estudio de la investigación es exploratorio porque mediante la obtención de información y definición del problema se fundamentará la base teórica contenida en el marco teórico, además aportar ideas o sugerencias que permitan proponer alternativas de solución a la problemática y de esta forma poder establecer las conclusiones del respectivo trabajo de investigación.

El instrumento utilizado en este proyecto es el cuestionario, que contiene 11 preguntas de tipo cerradas con dos alternativas de respuesta y 7 preguntas de tipo abiertas donde dejan en libertad al informante de exponer su opinión y análisis del tema que se investigará.

\section{Resultados}

En su mayoría, los encuestados opinan que es necesario judicializar los casos de violación de los derechos humanos ante la Corte Interamericana para ejercer control y evitar la impunidad de los Estados infractores.

En su mayoría, opinaron que la responsabilidad internacional no debe limitarse únicamente a una indemnización pecuniaria para la víctima.

La mayoría opinó que sí es importante, además de una indemnización pecuniaria para la víctima, una reparación total del daño ocasionado.

\section{Conclusión}

Según los hallazgos a través de diferentes autores y de los datos recopilados en la investigación de campo, se hace un análisis crítico en relación con los objetivos de la investigación, que se presenta a continuación. 
Determinar cuál es la importancia de judicializar los casos de violación de derechos humanos ante la Corte Interamericana de Derechos Humanos (CIDH).

Establecer el procedimiento que se seguirá en los casos de violación de los derechos humanos para solicitar la intervención de la Corte.
Según doctrina y la investigación de campo, judicializar los casos de violación de derechos humanos ante la CIDH radica en que la pecuniaria, así también con la judicialización de los casos se pretende proteger el derecho a la "verdad" en informar a todas las personas sobre todos los casos de violación a los derechos humanos que se han denunciado y cómo estos se han sancionado. víctima reciba una integra reparación del daño ocasionado y que esta no quede limitada únicamente a una indemnización.

Un caso puede ser sometido a la Corte únicamente por la $\mathrm{CIDH}$ o por un Estado Parte. En el primer caso, el proceso inicia con la presentación del Informe de Fondo proferido de conformidad con el Artículo 50 de la Convención, por parte de la CIDH. En el segundo, un Estado podrá someter un caso ante la Corte por escrito motivado y con la copia del expediente que se surtió ante la $\mathrm{CIDH}$.

No existe norma jurídica interna que, como consecuencia de dicha jurisprudencia, vaya más allá de los alcances de las disposiciones de la Convención Americana sobre Derechos Humanos. Es más, podría afirmarse que la jurisprudencia salvadoreña ni siquiera se ha planteado ese asunto, puesto que se encuentra en una fase anterior, como la disputa por la existencia o no de un bloque de constitucionalidad, es decir, si los tratados internacionales sobre derechos humanos son integrados o no a la Constitución de la República y, en consecuencia, si pueden o no servir de parámetro para el control de la constitucionalidad de las leyes. La posición jurisprudencial dominante ha sido la de rechazar el bloque de constitucionalidad, aunque esa corriente comenzó a ceder con la sentencia de inconstitucionalidad de la llamada Ley Antimaras (LAM), en la que se estableció que si una ley viola la Convención sobre los Derechos del Niño constituye también una violación al artículo 144.2 de la Constitución de la República, que establece la prevalencia de los tratados internacionales sobre las normas secundarias. 


\section{Recomendaciones}

Que el procurador para la Defensa de los Derechos Humanos de El Salvador tenga más protagonismo, e invite a los procuradores de Guatemala, Honduras, Costa Rica y Nicaragua para promover y proteger los sagrados derechos humanos.

Que el Estado de El Salvador promueva programas y proyectos educativos de promoción y aplicación de los derechos humanos mediante las diferentes instituciones que tutelan dichos derechos, lo cual permita hacer posible que la sociedad salvadoreña desarrolle la práctica de una convivencia de valores humanos universales como indicador de desarrollo humano.

Se le recomienda al procurador para la Defensa de Ios Derechos Humanos de El Salvador que tenga más protagonismo y que invite a los procuradores de Guatemala, Honduras, Costa Rica y Nicaragua para promover y proteger los sagrados derechos humanos.

Que el Estado de El Salvador promueva programas y proyectos educativos de promoción y aplicación de los derechos humanos a través de las diferentes instituciones que los tutelan, lo cual permita hacer posible que la sociedad salvadoreña desarrolle la práctica de una convivencia de valores humanos universales como indicador de desarrollo humano.

\section{Referencias}

Faúndez Ledesma, H. (2004). El Sistema Interamericano de Protección de los Derechos Humanos. Aspectos institucionales y procesales. Tercera edición. Instituto Interamericano de Derechos Humanos. San José (Costa Rica).

Martínez, J. (2010). El sistema interamericano de protección de los derechos humanos y el Derecho Penal Internacional. Konrad-Adenauer-Stiftung E. V. Montevideo, Uruguay.

Manual Popular del Órgano Judicial para la protección de los derechos humanos, primera edición 2012, Fundación Comisión de Derechos Humanos de El Salvador (CDHES).

Miguel Antonio D’Estéfano Pisani, Historia del Derecho Internacional. Editorial de Ciencias Sociales, la Habana (1988). 